UDC 316.776 .22

LBC 60.8

\title{
ON THE CLASSIFICATION OF FAKE INFORMATION DURING THE CORONAVIRUS PANDEMIC
}

\author{
Marina O. Zyryanova \\ Belgorod State Technological University, Belgorod, Russian Federation
}

\begin{abstract}
This article presents the classification of fakes on grounds of the information source that underlies the occurrence of false information. The study was perfomed on the coronavirus fakes that spread in Russian Federation in March 2020 during the beginning of the coronavirus pandemic in our country. For the analysis, only those fakes were taken, which the Administrations of the Russian regions promptly denied in their official accounts on social networks. Based on this, only those fakes that caused the greatest public response were selected for analysis. In this article, the following types of fakes are distinguished: folklore, symmetric, interpretive, additional, and conspiracy. Folklore fakes in various variations reproduce the same motives and are associated with well-established ideas and stereotypes in the mass consciousness. Symmetrical fakes partially or completely transfer true facts from one territory (country, region) to another. They can also transfer information from one person (structure) to another (s). Interpretative fakes are associated with the incorrect interpretation of events, information disseminated, or decisions made by the authorities by individual individuals. Additional fakes for a short period of time continue the theme of previously thrown disinformation. Conspiracy fakes are associated with conspiracy theory, characterized by stuffing on a wide territory and a large audience This classification is not exhaustive and can be supplemented as new fakes appear and are studied. Also, within the framework of this article, recommendations are given on how to refute a particular fake, depending on its belonging to a particular type.

Key words: fakes, classification fakes, a refutation of the fakes, folklor fakes, symmetrical fakes, interpretation fakes, additional fakes, conspiracy fakes.
\end{abstract}

Citation. Zyryanova M.O. On the Classification of Fake Information During the Coronavirus Pandemic. Logos et Praxis, 2021, vol. 20, no. 2, pp. 124-131. (in Russian). DOI: https://doi.org/10.15688/lp.jvolsu.2021.2.14

УДК 316.776 .22

ББК 60.8

\section{К ВОПРОСУ О КЛАССИФИКАЦИИ ФЕЙКОВОЙ ИНФОРМАЦИИ В ПЕРИОД ПАНДЕМИИ КОРОНАВИРУСА}

\author{
Марина Олеговна Зырянова \\ Белгородский государственный технологический университет им. В.Г. Шухова, \\ г. Белгород, Российская Федерация
}

\begin{abstract}
Аннотация. В данной статье представлена классификация фейков, созданная автором на основании информационного источника. Исследование проводилось на материале коронавирусных фейков, которые распространялись на территории Российской Федерации в марте 2020 г. в период начала пандемии. Для анализа были взяты только те фейки, которые Администрации российских регионов оперативно опровергали в своих официальных аккаунтах в социальных сетях. Исходя из этого, для анализа были отобраны только те «фейки», которые вызывали наибольший общественный резонанс. В данной статье выделяются следующие типы фейков: фольклорные, симметричные, интерпретационные, дополнительные, конспирологические. Фольклорные фейки в различных вариациях воспроизводят одни и те же мотивы и связаны с устоявшимися в массовом сознании представлениями и стереотипами. Симметричные фейки частично или полностью пере๓े носят правдивые факты с одной территории (страны, региона) на другую, с одного лица (структуры) на (?) другое(-ую). Интерпретационные фейки связаны с неверной трактовкой отдельными индивидуумами про-
\end{abstract}


исходящих событий, распространяемой информации, или принимаемых властью решений. Дополнительные фейки в течение небольшого периода времени продолжают тематику ранее вброшенной дезинформации. Конспирологические фейки связаны с теорией заговора, характеризуются распространением на большой территории и рассчитаны на широкую аудиторию. Данная классификация не является исчерпывающей и может дополняться по мере появления и изучения новых фейков. Также в рамках данной статьи даны рекомендации по способам опровержения фейков того или иного типа.

Ключевые слова: фейк, классификация фейков, опровержение фейков, фольклорные фейки, симметричные фейки, интерпретационные фейки, дополнительные фейки, конспирологические фейки.

Цитирование. Зырянова М. О. К вопросу о классификации фейковой информации в период пандемии коронавируса // Logos et Praxis. - 2021. - T. 20, № 2. -C. 124-131. - DOI: https://doi.org/10.15688/lp.jvolsu.2021.2.14

Пандемия коронавируса, охватившая мир в начале 2020 г., с самого начала сопровождалась небывалым всплеском распространения фейков. Последние «гуляли» не только внутри стран, но и переходили из одного государства в другое, обрастая новыми подробностями. Если же они распространялись внутри одной страны, то зачастую попадали из одного региона в другой. Исследователь А.В. Манойло считает это явление очень опасным оружием за счет того, что с их помощью можно управлять сознанием людей [Манойло web]. По мнению Ю.М. Ершова, фейк является серьезным инструментом коммуникационной стратегии, а журналисты используются как способ их внедрения [Ершов 2018, 245-256].

Целью данного исследования является анализ актуальной фейковой информации, которая появилась в самом начале пандемии коронавируса, с целью ее дальнейшего и более глубокого изучения.

В рамках данной статьи были проанализированы основные коронавирусные «фейки», которые в течение марта 2020 г. распространялись на территории Российской Федерации и которые Администрации российских регионов официально опровергали в своих аккаунтах в социальных сетях. Таким образом, в рамках нашего исследования была проанализирована не вся фейковая информация о коронавирусе, а именно те выявленные фейки, которые наносили максимальный вред стабильности в обществе в указанный промежуток времени. На уровне администрации регионов освещаются только самые важные события в пределах территории.

Необходимо отметить, что «пандемия фейков» в России началась в первой половине марта, когда одновременно в различных регионах России начала распространяться ин- формация о большом числе зараженных коронавирусом в Москве. Было разослано почти 10 тыс. сообщений в социальных сетях и мессенджерах о якобы 20 тыс. зараженных коронавирусом россиянах. Фейки о вирусе распространялись в социальной сети «ВКонтакте» с помощью ботов, также были использованы «вбросы» в мессенджерах. Целевой аудиторией сообщений стали чаты родителей школьников и дошкольников, а также форумы молодых мам [Истомина, Болецкая, Никольский web].

Ввиду важности и новизны проблемы в ходе специального совещания Президент России Владимир Путин уделил данному вопросу особенное внимание, отметив, что бороться с распространением фейков можно только предоставляя достоверную информацию гражданам [Совещание... web].

Следует отметить, что начиная с 15 марта 2020 г. число фальшивых новостей, распространяемых на территории России, начало стремительно увеличиваться. При этом практически все заметные мартовские фейки появились во второй половине месяца. В их число вошли сведения: о числе заболевших и умерших от коронавируса в различных регионах России; о грабеже квартир людьми в медицинских и химических костюмах или сотрудниками администраций под видом проведения дезинфекции; о полицейских патрулях в торговых центрах и школах; о дезинфекции городов с помощью распыления специальных веществ с вертолетов; о переброске войск и введении комендантского часа в Москве. Все эти фейки практически одновременно распространялись на территории многих регионов России.

Анализ таких ложных новостей позволил выделить пять групп на основании информа- 
ционного фона, который спровоцировал появление того или иного фейка. Следует отметить, что данная классификация не является исчерпывающей и дальнейший анализ может способствовать вычленению как новых групп информации, так и новых подходов к ее классификации [Iknoor, Deepak, Anoop 2020; Ahmed, Traore, Saad 2017]. Также важно отметить, что в отдельных случаях грань между разными группами фейков является очень тонкой:

1. Фольклорные, народные, типовые или универсальные фейки. В различных вариациях воспроизводят одни и те же мотивы и связаны с устоявшимися в массовом сознании представлениями и стереотипами. Такие фейки могут появляться в разное время, особенно кризисное, с разными по длительности перерывами. Фейки данного типа, связанные с коронавирусом, характеризовались одновременными «вбросами» на широких территориях (в разных странах, регионах). Как правило, они используются для информационной атаки, характеризуются широким географическим охватом и большой аудиторией. Распространение такого характера ложных новостей опасно, требует немедленного реагирования.

2. Симметричные фейки. Частично или полностью переносят правдивые факты с одной территории (страны, региона) на другую, с одного лица (структуры) на другое(-ую). Могут использоваться для информационной атаки и быть связанными как с целенаправленной дезинформацией, так и с непониманием конкретными эмоционально неустойчивыми личностями сложившейся ситуации. Распространение такого рода ложных сведений опасно, требует немедленного реагирования и опровержения.

3. Интерпретационные фейки. Связаны с неверной трактовкой происходящих событий, распространяемой информации, или принимаемых властью решений. Они могут использоваться для информационной атаки с целью раскачать ситуацию в обществе. Также могут ненамеренно порождаться отдельными эмоционально неустойчивыми личностями. Распространение такого рода фейков опасно, требует немедленного реагирования и опровержения.

4. Дополнительные фейки. В течение небольшого периода времени продолжают тематику ранее распространенной дезинформации. Они могут использоваться для локальной информационной атаки, поскольку их актуальность быстро пропадает. Опровержение упрощено тем, что ведется по готовому шаблону.

5. Конспирологические фейки. Связаны с теорией заговора, характеризуются распространением на большой территории и рассчитаны на широкую аудиторию.

К фольклорным фейкам мы относим дезинформацию, распространенную в виде голосового сообщения в начале марта 2020 г. о 20 тыс. заболевших коронавирусом в Москве. Необходимо отметить, что появление ложных сведений о количестве умерших или зараженных характерно для любых кризисных и чрезвычайных событий в России, произошедших в последние годы.

К числу фольклорных фейков мы также относим информацию, распространившуюся в середине марта 2020 г. в российских регионах, о людях в медицинских и химических костюмах, которые под предлогом дезинфекции квартир пускали слезоточивый газ и грабили жителей [Белозерцев web]. В некоторых случаях фигурировали сотрудники администрации [Парфенчиков web]. Данный «фейк» эксплуатирует устоявшуюся в массовом сознании мошенническую схему, когда грабители заходят в квартиры под видом сантехников, электриков, сотрудников социальных служб и проч. Как правило, их целью являются незащищенные слои населения, в первую очередь пенсионеры и дети. Следует отметить, что именно в это время во многих регионах началось свободное посещение школ, соответственно, большое число детей остались дома одни. Также в это время появились рекомендации для пенсионеров не покидать свои квартиры и отказаться от социальных контактов даже с родственниками в целях профилактики коронавируса. Наличие соответствующей реальной информационной картины позволило наложенному на нее фейку стать одним из наиболее распространяемых в марте 2020 года.

Еще одним примером фольклорного фейка можно считать ложные данные о распылении с вертолетов лекарства для дезинфекции, в связи с чем балконы и окна должны быть закрыты [Коллеги... web]. Этот фейк волной 
прокатился по российским регионам и соседним государствам, в том числе Беларуси, Грузии, Украине [Специалист объяснил... web] в середине марта 2020 года. Необходимо уточнить, что такие фальшивые сведения не являются новыми, десять лет назад они уже проходили по российским регионам во время эпидемии свиного гриппа 2009-2010 гг:: «Тогда подобные слухи расходились “живьем”, в общественном транспорте и между коллегами, а также посредством LiveJournal и СМИ» [Вилков web].

Симметричным фейком мы считаем распространенную в конце марта 2020 года по некоторым регионам информацию об их полной или частичной транспортной изоляции. В частности, 30 марта 2020 г. в Алтайском крае появились сведения о якобы перекрытом движении на трассе по бийскому направлению [Очередной фейк... web]. В свою очередь, ГУ МВД России по Алтайскому краю оперативно дало опровержение [ГУ МВД России... web]. Похожий фейк о закрытии региона был распространен в Волгоградской области. [Коронавирус... web]. Это происходило на фоне принятия решения в Австралии об ограничении транспортного движения 24 марта 2020 г. [Австралийские штаты... web]. В Республике Чечня с 28 марта 2020 г. было ограничено внутреннее перемещение [В Чечне... web]. Этот фейк заимствовал идею об ограничении передвижения из-за границы, его можно причислить к симметричным.

Самыми многочисленными среди симметричных мы считаем фейки о числе людей, заразившихся коронавирусом и умерших от этой болезни. Такие данные постоянно возникали в российских регионах в марте 2020 г. после появления фейка о количестве заболевших в Москве. Информация по аналогии распространялась в Брянской области, Вологодской области, Приморском крае, Республике Алтай и проч.

К интерпретационным фейкам мы относим, например, приказ под видом официального документа МЧС РФ - приказа Министра обороны РФ С. Шойгу - о введении в г. Москва комендантского часа с 30 марта 2020 г. с 20:00 до 05:00 [Фейковый приказ... web]. Необходимо отметить, Министерство обороны РФ официально опровергло эту информацию
18 марта 2020 года. Накануне, 17 марта 2020 г., газета «Ведомости» со ссылкой на собственные источники сообщила, что в Москве может быть введен комендантский час [Ляув, Ищенко web]. Оперативный штаб по контролю и мониторингу ситуации с коронавирусом опроверг эти данные. Вечером 16 марта 2020 г. Президент Франции Эмманюэль Макрон заявил о закрытии границ Евросоюза с 17 марта [Лисицына web]. С нашей точки зрения, фейк интерпретировал данные, которые обсуждали зарубежные и российские средства массовой информации.

Еще один интерпретационный фейк - о досрочном окончании учебного года - распространился в социальных сетях [Министерство просвещения... web], и 26 марта 2020 г. его опровергло Министерство просвещения РФ. Информация появилась на фоне рекомендации Минпросвещения РФ при необходимости временно переводить учеников на дистанционное обучение. В ряде регионов, в частности в Санкт-Петербурге, дистанционное обучение началось 6 апреля. 27 марта 2020 г. информационное агентство «Итар-тасс» распространило заявление Министерства просвещения о том, что структура примет решение о необходимости продления каникул, исходя из эпидемиологической ситуации в стране, и озвучит его регионам к середине следующей недели [Минпросвещения... web]. Таким образом, этот фейк возник на фоне неверной интерпретации официальной информации.

Фейк о стягивании войск к Москве, который распространялся в конце марта 2020 г. [Новый фейк... web], мы относим к дополнительным, поскольку он продолжил ложную тему введения в Москве комендантского часа.

Конспирологические фейки всегда связаны с теорией заговора. В течение мартаапреля 2020 г. в Интернете распространялось много информации о том, что коронавирус - это генно-модифицированное биологическое оружие, которое создано для чипирования людей и установления глобального мирового порядка, а еще для уничтожения населения, которое будут заражать через вакцины. 6 мая 2020 г. Генеральная прокуратура Российской Федерации потребовала ограничить доступ к сайтам, где размещена недостоверная информация конспиро- 
логического характера о коронавирусе [Генеральная прокуратура... web].

Приведенная выше классификация может стать полезным инструментом для специалистов, которые работают с проблемой опровержения фейков: специалисты в области PR, политтехнологи, социологи. В зависимости от типа, к которому относится ложная информация, можно выбрать и стратегию ее опровержения. При этом зачастую дается лишь сухая справка о том, что распространенная информация не соответствует действительности и необходимо пользоваться данными, размещенными на официальных ресурсах.

В частности, при опровержении фольклорных фейков можно указать те «народные мотивы», которые лежат в основе образования данного фейка. Также можно привести примеры, каким образом данные мотивы ранее использовались при распространении фейков и слухов.

При опровержении симметричных фейков необходимо обязательно указывать исходный материал, на основании которого была сфабрикована информация. Таким образом, опровержение будет восприниматься как более убедительное и распространение ложных данных быстро прекратится само собой.

Интерпретационные фейки опровергнуть, с нашей точки зрения, сложнее всего, так как они часто рождаются в процессе обсуждения еще не принятых решений. Поэтому не всегда возможно четко отослать аудиторию к решению, принятому в действительности, однако это необходимо делать.

Дополнительные фейки опровергать проще всего: необходимо вспомнить распространенную ранее информацию, акцентировать внимание на уточнениях и дополнениях, которыми оброс фейк, и повторить опровержение.

Конспирологические фейки опровергать крайне сложно, потому что они базируются на устойчивом стереотипе - власти обманывают людей. Такие ложные данные излишне эмоциональны, строятся на страхах и фобиях, зачастую при их формировании используются знания из области психологии. При опровержении таких фейков необходимо исходить из фактов и научных знаний.

При выявлении и опровержении информации необходимо помнить, что часто фейк от настоящей новости отличается отсутствием подтверждения заявленной информации. В сообщениях подобного рода ведется работа с эмоциями [Зуйкина, Соколова 2019, 17].

\section{СПИСОК ЛИТЕРАТУРЫ}

Австралийские штаты... web - Австралийские штаты закрывают свои внутренние границы изза распространения коронавируса [Информационное агентство ИТАР-ТАСС. 24.03.2020] // https://tass.ru/obschestvo/8060649.

Белозерцев И. web - Белозериев И. Внимание!!! По домам ходят люди [Официальная страница Губернатора Пензенской области Ивана Белозерцева в социальной сети «ВКонтакте»] // https:/ /vk.com/id572326065?w=wall572326065_3108.

Вилков C. web - Вилков C. Легенда о вертолете: откуда берутся фейки про коронавирус и как их опознать [News.ru] // https://news.ru/investigations/ opylyaj-i-vlastvuj-otkuda-berutsya-fejki-prokoronavirus-i-kak-ih-otlichit.

В Чечне... web - B Чечне ограничат движение через границы республики из-за COVID-19 [PИА «Новости»] ]/https://ria.ru/20200329/1569299902.html.

Генеральная прокуратура... web - Генеральная прокуратура Российской Федерации требует ограничить доступ к сайтам [Официальный сайт Генеральной прокуратуры РФ] // http://www.genproc. gov.ru/smi/news/genproc/news-1836600/.

ГУ МВД России... web - ГУ МВД России по Алтайскому краю разьясняет! [Главное управление МВД России по Алтайскому краю] // https:// 22.мвд.pф/news/item/19883191.

Ершов 2018 - Ершов Ю.М. Феномен фейка в контексте коммуникационных практик // Вестник Томского государственного университета. Филология. 2018. № 52. С. 245-256.

Зуйкина, Соколова 2019 - Зуйкина К.Л., Соколова Д.В. Специфика контента российских фейковых новостей в Интернете и на телевидении // Вестник Московского университета. Серия 10, Журналистика. 2019. № 4. С. 3-22.

Истомина, Болецкая, Никольский web - Истомина М., Болеикая К., Никольский К. В России массово распространяются фейки об эпидемии коронавируса [Ведомости] // https:// www.vedomosti.ru/media/articles/2020/03/02/ 824255-epidemii-koronavirusa.

Коллеги... web - Коллеги, у кого такая рассылка была? [Официальная страница Правительства Республики Карелия в социальной сети «ВКонтакте»] // https://vk.com/gov_karelia ru? $\mathrm{z}=$ photo-134397408_457267525\%2Fwall13439740839609. 
Коронавирус... web - Коронавирус - это серьезно [Официальная страница Правительства Вологодской области в социальной сети «ВКонтакте»] // https://vk.com/vologda?w=wall24699245232047.

Лисицына web - Лисицына М. Макрон объявил о закрытии въезда в Шенген с 17 марта [РосБизнесКонсалтинг] // https://www.rbc.ru/society/ 16/03/2020/5e6fd7fc9a7947b44540439b.

Ляув, Ищенко web - Ляув Б., Ищенко Н. Москва может закрыться на карантин [Ведомости] // https://www.vedomosti.ru/society/articles/ 2020/03/17/825437-moskva-mozhet-zakritsyana-karantin.

Манойло web - Манойло А.B. Цепные реакции каскадного типа в современных технологиях вирусного распространения «фейковых новостей» [Вестник Московского государственного областного университета (электронный журнал). 2020. № 3] // http://ruspolitology.ru/ content/10391/.

Министерство просвещения... web - Министерство просвещения опровергло недостоверную информацию об организации образовательного процесса [Официальный сайт Министерства просвещения РФ] // https:/edu.gov.ru/ press $/ 2253 / \mathrm{ministerstvo-prosvescheniya-}$ oproverglo-nedostovernuyu-informaciyu-oborganizacii-obrazovatelnogo-processa.

Минпросвещения... web - Минпросвещения на следующей неделе сообщит, будут ли продлены каникулы в школах [ИТАР-ТАСС] // https:// tass.ru/obschestvo/8097371.

Новый фэйк... web - Новый фэйк распространяют в мессенджерах и соцсетях [Официальная страница Правительства Приморского края в социальной сети «ВКонтакте»] // https:// vk.com/primorskykray?w=wall-150272757_7958.

Очередной фейк... web - Очередной фейк - о перекрытой из Барнаула до Бийска трассе - опровергают алтайские полицейские [Официальная страница Правительства Алтайского края в социальной сети «ВКонтакте»] // https:// vk.com/altairegion22?w=wall-39933875_15752.

Парфенчиков web - Парфенчиков А. Уважаемые жители республики, будьте бдительны [Официальная страница Правительства Республики Карелия в социальной сети «ВКонтакте»] // https:// vk.com/gov_karelia_ru?w=wall419407976_121833.

Совещание... web - Совещание с членами Правительства [Официальный сайт Президента РФ] // http://www.kremlin.ru/events/president/news/ 62930.

Специалист объяснил... web - Специалист объяснил ситуацию с «распылением» антисептиков с вертолетов над городами из-за корона- вируса COVID-19 [Avia.pro] // https://avia.pro/ news/specialist-obyasnil-situaciyu-s-raspyleniemantiseptikov-s-vertolyotov-nad-gorodami-iz-za.

Фейковый приказ... web - Фейковый приказ Министра обороны РФ [Официальная страница Правительства Ивановской области в социальной сети «ВКонтакте»] // https://vk. com/ivanovo? $\mathrm{z}=$ photo-23491940_457251498 \%2Fwall-23491940 15212.

Ahmed, Traore, Saad 2017 - Ahmed H., Traore I., Saad S. Detection of Online Fake News Using N-Gram Analysisand Machine Learning Techniques. International Conference on Intelligent, Secure, \& Dependable Systems in Distributed \& Cloud Environments // https:// www.researchgate.net/publication/320300831 Detection_of_Online_Fake_News_Using N-Gram_Analysis_and_Machine_Learning_ Techniques.

Iknoor, Deepak, Anoop 2020 - Iknoor S., Deepak P., Anoop K. On the Coherence of Fake News Articles [ $8^{\text {th }}$ International Workshop on News Recommendation and Analytics (INRA 2020) Held in Conjunction with ECMLPKDD] // https:// arxiv.org/pdf/1906.11126.pdf.

\section{REFERENCES}

Australian States are Closing Their Internal Borders Due to the Spread of the Coronavirus. ITARTASS. URL: https://tass.ru/obschestvo/8060649.

Belozertsev I. Attention!!! People Go to Their Homes. The Official Page of the Governor of the Penza Region Ivan Belozertsev in the Social Network "VKontakte”. URL: https:// vk.com/id572326065?w=wall572326065 3108.

Vilkov S. The Legend of the Helicopter: Where do the Fakes About the Coronavirus Come from and How to Identify Them. News.ru. URL: https:// news.ru/investigation s/opylyaj-i-vlastvujotkuda-berutsya-fejki-pro-koronavirus-i-kak-ihotlichit.

Traffic Across the Republic's Borders Will Be Restricted in Chechnya Due to COVID-19. RIA Novosti. URL: https://ria.ru/20200329/ 1569299902.html.

The Prosecutor General's Office of the Russian Federation Demands to Restrict Access to the Sites. Official Website of the Prosecutor General's Office of the Russian Federation. URL: http://www.genproc.gov.ru/smi/news/ genproc/news-1836600/.

GU of the Ministry of Internal Affairs of Russia in the Altai Territory Explains! The Main Department of the Ministry of Internal Affairs of Russia in 
the Altai Territory. URL: https://22.мвд.рф/ news/item/19883191/.

Yershov Yu.M., 2018. The Phenomenon of Fake in the Context of Communication Practices.Vestnik Tomskogo gosudarstvennogo universiteta. Philology, no. 52, pp. 245-256.

Zuikina K.L., Sokolova D.V., 2019. Specificityof theContent of Russian Fake News on the Internet and on Television. Vestnik Moskovskogo universiteta. Seriya 10, Zhurnalistika, no. 4, pp. 3-22.

Istomina M., Boletskaya K., Nikolsky K., 2020. In Russia, Fakes About the Coronavirus Epidemic are Massively Distributed. Vedomosti. URL: https:/www.vedomosti.ru/media/articles/2020/ 03/02/824255-epidemii-koronavirusa.

Colleagues, Who Had Such a Newsletter? Official Page of the Government of the Republic of Karelia in the Social Network "VKontakte". URL: https://vk.com/gov karelia ru?z=photo$134397408 \quad 457267525 \% 2 F w a l l-13439740839609$.

Coronavirus is Serious Web-Coronavirus is Serious. Official Page of the Government of the Vologda Region in the Social Network "VKontakte". URL: https://vk.com/vologda?w=wall-24699245_232047.

Lisitsyna M. Macron Announced the Closure of the Entrance to the Schengen Area from March 17. RosBusinessConsulting. URL: https://www.rbc. $\mathrm{ru} /$ society/16/03/2020/5e6fd7fc9a7947b44540439b.

Lyauv B., Ishchenko N., 2020. Moscow Can Be Closed for Quarantine. Vedomosti. URL: https:// www.vedomosti.ru/society/articles/2020/03/17/ 825437-moskva-mozhet-zakritsya-na-karantin.

Manoilo A.V., 2020. Chain Reactions of Cascade Type in Modern Technologies of Viral Distribution of "Fake News". Bulletin of the Moscow State Regional University (Electronic Journal), no. 3. URL: http://ruspolitology.ru/content/10391/.

The Ministry of Education Has Denied False Information About the Organization of the Educational Process. Official Website of the Ministry of Education of the Russian Federation. URL: https://edu.gov.ru/press/ 2253/ministerstvo-prosvescheniya-oproverglonedostovernuyu-informaciyu-ob-organizaciiobrazovatelnogo-processa.

Ministry of Education Next Week Will Report Whether the School Holidays Will Be Extended. ITARTASS. URL: https://tass.ru/obschestvo/8097371.
New Fake Distributed in Messengers and Social Networks. Official Page of the Government of Primorsky Krai in the Social Network "VKontakte". URL: https://vk.com/primorsky kray?w=wall-150272757_7958.

Another Fake - About the Road Blocked from Barnaul to Biysk - is Denied by the Altai Police. The Official Page of the Government of the Altai Territory in the Social Network "VKontakte". URL: https://vk.com/altairegion 22 ? $\mathrm{w}=$ wall39933875 15752.

Parfenchikov A. Dear Residents of the Republic, Be Vigilant. Official Page of the Government of the Republic of Karelia in the Social Network "VKontakte". URL: https://vk.com/ gov karelia_ru?w=wall419407976_121833.

Meeting with Members of the Government. Official Website of the President of the Russian Federation. URL: http:/www.kremlin.ru/events/ president/news/62930.

The Specialist Explained the Situation with the "Spraying" of Antiseptics from Helicopters over Cities Due to the COVID-19 Coronavirus. Avia.pro. URL: https://avia.pro/news/specialistobyasnil-situaciyu-s-raspyleniem-antiseptikovs-vertolyotov-nad-gorodami-iz-za.

Fake Order of the Minister of Defense of the Russian Federation. Official Page of the Government of the Ivanovo Region in the Social Network "VKontakte". URL: https://vk.com/ivanovo?z= photo-23491940 457251498\%2Fwall2349194015212.

Ahmed H., Traore I., Saad S. 2017. Detection of Online Fake News Using N-Gram Analysisand Machine Learning Techniques. International Conference on Intelligent, Secure, \& Dependable Systems in Distributed \& Cloud Environments. URL: https://www.researchgate.net/publication/ 320300831_Detection_of_Online_Fake_News Using_N-Gram_Analysis_and_Machine_ Learning_Techniques.

Iknoor S., Deepak P., Anoop K., 2020. On the Coherence of Fake News Articles. $8^{\text {th }}$ International Workshop on News Recommendation and Analytics (INRA 2020) Held in Conjunction with ECML PKDD. URL: https://arxiv.org/pdf/ 1906.11126.pdf. 
M.О. Зырянова. К вопросу о классификации фейковой информации в период пандемии коронавируса

\section{Information About the Author}

Marina O. Zyryanova, Postgraduate Student, Department of Sociology and Management, Belgorod State Technological University, Kostyukova St, 46, 308012 Belgorod, Russian Federation, synergy7@mail.ru, https://orcid.org/0000-0002-3937-4275

\section{Информация об авторе}

Марина Олеговна Зырянова, аспирант кафедры социологии и управления, Белгородский государственный технологический университет им. В.Г. Шухова, ул. Костюкова, 46, 308012 г. Белгород, Российская Федерация, synergy7@mail.ru, https://orcid.org/0000-0002-3937-4275 